\title{
1 On the Seasonality of Flooding Across the Continental United States 2
}

GABRIELE VILLARINI

6 IIHR-Hydroscience \& Engineering, The University of Iowa, Iowa City, Iowa, USA.

Manuscript submitted to

Advances in Water Resources

17 Corresponding author address:

18 Gabriele Villarini, IIHR-Hydroscience \& Engineering, The University of Iowa, 306 C. Maxwell

19 Stanley Hydraulics Laboratory, Iowa City, 52242, Iowa, USA. E-mail: gabriele-

20 villarini@uiowa.edu. Tel.: (319) 384-0596

21 
This study examines the seasonality of flooding across the continental United States using

3 circular statistics. Analyses are based on 7506 USGS stream gage stations with a record of least

430 years of annual maximum instantaneous peak discharge. Overall, there is a very strong

5 seasonality in flooding across the United States, reflecting differences in flood generating

6 mechanisms. Most of the flood events along the western and eastern United States tend to occur

7 during the October-March period and are associated with extratropical cyclones. The average

8 seasonality of flood events shifts to April-May in regions where snowmelt is the dominant flood

9 agent, and later in the spring-summer across the central United States. The strength of the

10 seasonal cycle also varies considerably, with the weakest seasonality in the Appalachian

11 Mountains and the strongest in the northern Great Plains. The seasonal distribution of flooding is

12 described in terms of circular uniform, reflective symmetric and asymmetric distributions. There

13 are marked differences in the shape of the distribution across the continental United States, with

14 the majority of the stations exhibiting a reflective symmetric distribution.

15 Finally, nonstationarities in the seasonality of flooding are examined. Analyses are

16 performed to detect changes over time, and to examine changes that are due to urbanization and

17 regulation. Overall, there is not a strong signal of temporal changes. The strongest impact of

18 urbanization and regulation is on the strength of the seasonal cycle, with indications that the 19 signal weakens (i.e., the seasonal distribution becomes wider) under the effects of regulation. 


\section{Introduction}

2 Understanding the seasonality of flooding is critical in a number of applications, from water

3 resources management and assessment of flood risk, to climate change studies and

4 regionalization (e.g., Archer et al. 1981; Burn 1997, Castellarin et al. 2001, Cunderlik and Burn

5 2001, Javelle et al. 2003, McCuen and Beighley 2003, Sivapalan et al. 2005, Ouarda et al. 2006,

6 Chowdhury and Ward 2007, Fang et al. 2007, Beurton and Thieken 2009, Rust et al. 2009, Chen

7 et al. 2010, 2013). Moreover, the analysis of seasonality is useful to characterize the variety of

8 different flood generating mechanisms (e.g., Rossi et al. 1984, Hirschboeck 1991, De Michele

9 and Rosso 2002, McEwen 2006, Villarini and Smith 2010, Smith et al. 2011).

10 The seasonality of flooding has been examined in different regions. Black and Werritty

11 (1997) analyzed 156 stream gages in northern Britain. Their analyses found that, while flood

12 events could occur during any day of the year, $78 \%$ of the flood events at the majority of the

13 stations were concentrated in the October-March period. Burn (1997) analyzed 59 natural

14 catchments in the Canadian Prairies and discussed similarities and differences in flood

15 seasonality across Alberta, Saskatchewan and Manitoba, and the implications for regional flood

16 frequency analysis. Cunderlik and Ouarda (2009) worked on the temporal changes in the flood

17 timing in Canada over the 1974-2003 period. They found that spring floods associated with

18 snowmelt in southern Canada (in particular in the Atlantic Provinces) tended to happen earlier

19 than in the past, but they did not detect significant changes in the timing of flooding in the fall.

20 Parajka et al. (2010) focused on annual maximum runoff and daily precipitation in the Alpine-

21 Carpathian range over the 1961-2000 period. They showed that the annual maxima typically

22 occurred in July-August in the Carpathian Arch and northern Alps, with a shift later in the year

23 for southern Austria and north-east Italy. Moreover, the results for annual maximum runoff were 
1 similar to precipitation, even though more heterogeneous. Koutroulis et al. (2010) examined the

2 seasonality of heavy rainfall and flooding for the island of Crete, and showed that the largest

3 events were concentrated in the November-December months. Macdonald (2012) analyzed

4 changes in the flood seasonality for the historical flood record for the River Ouse (northern

5 England) since AD 1600. He found an increase in the number of February-March flood events

6 since 1950. Köplin et al. (2014) studied the projected changes in the seasonality of annual

7 maximum discharge records at 189 catchments in Switzerland; they found that the strongest

8 signal of change in flood seasonality was detected at sites in which snowmelt played an 9 important role.

10 Various approaches have been used to describe flood seasonality (e.g., Black and Werritty 11 1997, Cunderlik et al. 2004, Chen et al. 2013), with the increasingly widespread use of circular 12 or directional statistics in recent years (e.g., Bayliss and Jones 1993, Magilligan and Graber 13 1996, Burn 1997, Cunderlik et al. 2004, Chen et al. 2010, 2013, Köplin et al. 2014, Dhakal et al. 14 2015).

15 Despite the importance of the topic for hydrology, flood hazard and water resources 16 management, a comprehensive characterization of the seasonality of flooding across the 17 continental United States and of its potential changes over time is still lacking, with existing 18 works that have only been performed at a regional or local scale. Magilligan and Graber (1996) 19 studied the seasonality of flooding for 36 stream gages in New England. They found that basin 20 size, altitude and distance from the coast were major controls on the strength of the seasonality. 21 Gamble (1997) examined the seasonality of annual flood peaks in the southeastern United States 22 using 84 stream gage stations. They identified five regions with similar seasonality (winter, 23 spring, spring/high summer, fall, no dominant season). Lecce (2000) focused on the seasonality 
1 of flooding in North Carolina, and divided the state into three regions (Appalachian, Piedmont

2 and Coastal Plain); about $75 \%$ of the floods occurred in the December-April period in the

3 Appalachian region, while this fractional contribution decreased in the Piedmont (44\%) and

4 Coastal Plain (55\%) regions. Summer and fall flooding occurs more frequently in the Piedmont

5 and Coastal Plain regions compared to the Appalachian region.

6 Moreover, we have little information related to changes in the seasonality of U.S. flooding

7 over the $20^{\text {th }}$ and $21^{\text {st }}$ centuries despite the importance of the impacts of changes in the

8 seasonality of extreme events on the built infrastructure (e.g., Dhakal et al. 2015). These

9 potential changes are related to changes in the climate system as well as anthropogenic

10 alterations of the catchments. Most of the efforts have focused on changes in runoff timing in the

11 western and north-eastern United States associated with springtime snowmelt shifted earlier in

12 the year (e.g., Hodgkins et al. 2003, Stewart et al. 2004, 2005, Barnett et al. 2005, McCabe and

13 Clark 2005, Clow 2010). However, much less is known about changes in the seasonality of

14 annual maximum discharge.

15 In considering potential nonstationarities, we have to remember that many of the watersheds

16 across the continental United States have been subject to human modifications, including

17 damming and construction of upstream reservoirs and urbanization. While a lot of effort has

18 been paid to the detection of changes in the flood peak records (e.g., Lins and Slack 1999,

19 Villarini et al. 2009, Vogel et al. 2011, Hirsch and Ryberg 2012, Peterson et al. 2013, Slater et al.

20 2015, Mallakpour and Villarini 2015), we have little information related to the impacts of

21 anthropogenic modifications on flood seasonality. When comparing urban to rural catchments,

22 Robson and Reed (1999) showed that urban watersheds tend to be characterized by summer

23 flooding (see also Bayliss and Jones (1993)), while the control rural watersheds exhibit mainly a 
1 winter seasonality. These differences are likely related to the larger effect of summertime

2 convective storms on urbanized watersheds. Moreover, the flood seasonality was wider (i.e.,

3 flood events could occur all year round) for urban than rural catchments.

4 Based on this brief overview, it is clear that a comprehensive characterization of the 5 seasonality of flooding across the continental United States, as well as of its changes, requires

6 further investigations. Therefore, the research questions I will address in this study are:

$7 \quad$ - What is the seasonality of flooding across the continental United States? Analyses will 8 examine basic descriptors (e.g., average seasonality and its strength) and will $9 \quad$ characterize the seasonal distribution.

10 - Can we detect a change in the seasonal cycle of flooding over the second half of the $20^{\text {th }}$ $11 \quad$ century and into the $21^{\text {st }}$ century?

12 - What are the effects of urbanization and regulation on the seasonality of flooding?

13 The paper is organized as follows. Section 2 summarizes the data and provides an overview 14 of the statistical methods (circular statistics) used to address the aforementioned research 15 questions. Section 3 presents the results, while the main findings are summarized and the study 16 concludes in Section 4.

18 2. Data and Methodology

19 The results of this work are based on instantaneous annual peak discharge data from 7506 20 U.S. Geological Survey (USGS) stream gage stations over the continental United States (Figure 21 1a). These stations have at least 30 years of data (in agreement with the recommendation by

22 Cunderlik et al. (2004)), with more than 5000 stations spanning the second half of the $20^{\text {th }}$ 23 century and the first decade of the $21^{\text {st }}$ century (Figure 1, panels b and c). To examine the impact 
1 of regulation, the focus is on stations that have at least 10 years of peaks with an associated code

26 ("Discharge affected by Regulation or Diversion") and at least 10 years without it. To examine

3 the impact of urbanization, the same criteria are applied but for peaks with the code C ("All or

4 part of the record affected by Urbanization, Mining, Agricultural changes, Channelization, or

5 other"). As shown in Supplementary Figure 1, there are 755 (241) stations that fit these criteria to

6 examine the impact of regulation (urbanization) on the flood peak seasonality.

7 Analyses of the seasonality of flooding across the continental United States in this study are

8 based on circular statistics. Here I provide a brief overview of circular statistics based on Pewsey

9 et al. (2013). For a thorough discussion on this topic, the interested reader is pointed to Mardia

10 (1972), Fisher (1993), and Pewsey et al. (2013), among others. I use annual maximum peak

11 discharge data from three stream gages to support the description and applicability of circular

12 statistics. Figure 2 shows three possible seasonal distributions that one can encounter across the

13 continental United States. The results in the left panels of Figure 2 are relative to the Roanoke

14 River at Roanoke Rapids, North Carolina (USGS ID 02080500), where annual maxima can

15 occur any time during the year without a preferential season. The two circles in the middle

16 column of Figure 2 are for the East Brach Penobscot River at Grindstone, Maine (USGS ID

17 01029500). Here the peak discharge maxima exhibit a strong seasonality, with peaks

18 concentrated during the April-May months. Finally, the results in the right column of Figure 2

19 are relative to the Souhegan River at Merrimack, New Hampshire (USGS ID 01094000). This

20 station exhibits an asymmetric distribution with most of the annual maxima in the March-May

21 period, but with peaks in the December-January months as well.

22 Circular statistics are appropriate for data that can be represented on a circumference with

23 unit radius. Similar to Pewsey et al. (2013), let us represent the angles in radians, and consider a 
1 circle of unit radius, with $\mathbf{x}=(\cos \theta, \sin \theta)$ relating the unit vector $\mathbf{x}$ and the angle $\theta$. We can

2 simplify the formulation by considering $\mathbf{x}$ on the complex rather than on the real plane, with the

3 horizontal (vertical) axis representing the real (imaginary) component. In the complex

4 representation, we can represent an observation with vector $\mathbf{x}$ as:

$5 \quad z=e^{i \theta}=\cos \theta+i \cdot \sin \theta$

6 where $i$ refers to $\sqrt{-1}$. Supplementary Figure 2 provides a graphical representation of the 7 circular observation in the complex plane.

8 For circular data, the sample mean direction $\bar{\theta}$ is the most widely used measure of location.

9 Figure 2 (bottom panels) shows the direction of each observation, together with the mean 10 resultant vector (black arrow) for each of the three stream gages. For the Roanoke River at 11 Roanoke Rapids (Figure 2, left panels), the mean direction is $336^{\circ}$, corresponding to December 12 2. On the other hand, the mean resultants for the East Brach Penobscot River at Grindstone 13 (Figure 2, middle panels) and for the Souhegan River at Merrimack (Figure 2, right panels) are $14116^{\circ}$ (corresponding to April 28) and $75^{\circ}$ (corresponding to March 17), respectively.

15 Figure 2 highlights that the mean direction provides some useful information, but that it 16 could also lead to misleading statements if not complemented by a measure of the strength of the 17 seasonality. This is particularly true for the uniform case, in which we can have flood events 18 throughout the course of the year. The spread in the data and the strength of the seasonality can

19 be quantified using the sample mean resultant length $\bar{R}$. The sample mean resultant length can 20 assume values from 0 to 1 , with values of 1 when all the points are concentrated at one location, 21 and values of 0 when the observations are uniformly distributed along the unit circle. This 22 quantity is represented by the length of the black solid arrows in Figure 2 (bottom panels). For 23 those three stations, the values of $\bar{R}$ are $0.07,0.65,0.62$, respectively. In addition to $\bar{R}$, there are 
1 other metrics that can be used to quantify concentration and dispersion in circular data, including

2 the sample circular variance, the sample circular dispersion, and the circular mean deviation.

3 As with the mean and dispersion, the probability distributions for circular data need to

4 account for the periodicity associated with these data. Therefore, a circular distribution function

$5 \quad F$ can be written such that:

$6 \quad F(\theta)=P(0 \leq \Theta \leq \theta), 0 \leq \theta \leq 2 \pi$

$7 \quad F(\theta+2 \pi)-F(\theta)=1,-\infty<\theta \leq+\infty$

8 Most of the classic circular models are reflective symmetric about a given axis $\psi$. If the

9 random variable $\Theta$ has a reflective symmetric distribution about $\psi$ with density $f(\theta)$, then

$10 f(\theta-\psi)=f(\psi-\theta)$. As in linear statistics, the sample measures related to location and

11 variability have population analogues. More specifically, one can consider the mean direction $\mu$

12 and the mean resultant length $\rho$, for which the sample measures $\bar{\theta}$ and $\bar{R}$ represent the point

13 estimates.

14 The most fundamental circular model is represented by the continuous circular uniform

15 distribution. In this case, there is no preferential direction, $\rho$ is equal to zero and $\mu$ is undefined.

16 There are no parameters to estimate and the circular uniform distribution is characterized by

17 circular randomness. Among the different continuous circular models, Pewsey et al. (2013) list

18 the cardioid, Cartwright's power-of-cosine, wrapped Cauchy and normal, von Mises, Jones-

19 Pewsey family, and the inverse Batschelet family (chapter 4).

20 From an inferential perspective, the first step is to examine whether or not we can reject the

21 null hypothesis of circular uniformity. If we cannot reject it, then there is no need to consider

22 more complex models. The Rayleigh test allows testing for unimodal departures from

23 uniformity. It examines whether the value of $\bar{R}$ is larger than a threshold value, leading to the 
1 rejection or not of the null hypothesis of uniformity. While the Rayleigh test is designed to test

2 for unimodal departures from uniformity, there are more general omnibus tests for uniformity,

3 such as Kuiper's $\mathrm{V}_{\mathrm{n}}$, Watson's $\mathrm{U}^{2}$, and Rao's spacing test; however no test systematically

4 outperforms the others under all circumstances. Unless there is an a priori reason to expect the

5 data to be unimodal, then the Kuiper's $\mathrm{V}_{\mathrm{n}}$, Watson's $\mathrm{U}^{2}$, and Rao's spacing test are

6 recommended (Pewsey et al. 2013). Here I consider all four of these tests (Rayleight test,

7 Kuiper's $V_{n}$, Watson's $U^{2}$, and Rao's spacing test) to examine whether the null hypothesis of

8 uniformity can be rejected.

9 If the null hypothesis of uniformity can be rejected at the $5 \%$ significance level based on any

10 of the aforementioned uniformity tests, I move forward with the examination of more complex

11 models to describe the data, starting with the test for reflective symmetry about an unknown

12 central direction as presented in Pewsey (2002). There are two versions of this test depending on

13 the sample size. If the sample size is larger than 50 , then the asymptotic theory can be used;

14 otherwise, for smaller sample sizes the bootstrap version is recommended. Based on the sample

15 size (larger than 50 or not) the suggested version of the test is used in this study. I set a

16 significance level $\alpha$ equal to $5 \%$. If there is enough statistical evidence to reject the null

17 hypothesis of reflective symmetry, the seasonality is considered as asymmetric, which also

18 includes multimodal models (i.e., finite mixtures of unimodal symmetric and asymmetric

19 models).

20 In performing the above calculations, I have implicitly assumed that the distribution of the

21 seasonality of flooding is stationary. Here these records are tested for the presence of possible

22 temporal nonstationarities and the effects that human modifications of the watersheds (regulation

23 and urbanization) may have exerted on the seasonality of flooding are examined. Testing for the 
1 presence of temporal changes in the seasonality of flooding is performed by considering

2 measures of linear-circular association, in which there is one linear variable X (i.e., time) and

3 one circular random variable $\Theta$ (i.e., day of the annual maximum peak discharge). The Johnson-

4 Wehrly-Mardia correlation coefficient (Mardia 1976, Johnson and Wehrly 1977) is a parametric

5 test of linear-circular association (it assumes that the association is approximately sinusoidal),

6 with values ranging between 0 (i.e., independence between $X$ and $\Theta$ ) and 1 (i.e., the larger the

7 value, the stronger the association). The statistical significance of the test is computed using a

8 randomization test (Pewsey et al. 2013). A commonly used nonparametric test for linear-circular

9 association is the Mardia's rank correlation coefficient (Mardia 1976). It follows the reasoning

10 behind the Spearman's rank test by using the ranked data and makes less restrictive assumptions

11 than the parametric counterpart. The significance of the test statistic can be quantified using a

12 randomization version of the test. A disadvantage of these tests is that it is not possible to 13 quantify the sign of the relationship (e.g., Lee 2010).

14 The effects of urbanization and regulation on the seasonality of flooding are evaluated by

15 focusing on potential changes in the mean, concentration, and distribution of the data. These

16 analyses are performed by comparing the years with and without the code "6" (for regulation) or

17 the code "C" (for urbanization). I use the Watson large-sample nonparametric test (e.g., Fisher

18 1993) to test the null hypothesis of a common mean direction of the two distributions. In contrast

19 to other similar tests, the Watson's test does not assume that the data come from distributions

20 with common dispersion or shape. Depending on the sample size (25 observations or larger), the

$21 \mathrm{p}$-value of the test is either computed with respect to a chi-squared distribution or by means of

22 bootstrap (if smaller than 25). The differences are tested by setting a significance level of $5 \%$.

23 The Wallraff's nonparametric test (Wallraff 1979) is used to test for differences in concentration, 
1 with a significance level of 5\%. Finally, the Watson's two sample test (Watson 1962), a special

2 case of the Mardia-Watson-Wheeler test (Wheeler and Watson 1964, Mardia 1972), is used to

3 test whether the two samples are drawn from the same distribution.

4

5

\section{$6 \quad 3$. Results}

9 information about the time of the year in which flood events tend to occur, and how strong the

10 seasonality is. The seasonality of flooding across the continental United States exhibits very

11 strong regional features. The U.S. West Coast (western Washington, western Oregon and coastal

12 California) is characterized by flooding mostly during the cold season, with sample mean

13 directions concentrated in the December-January period. These flood events are often associated

14 with atmospheric rivers, which are long and narrow atmospheric feature transporting moisture

15 from the tropics to the midlatitudes (e.g., Ralph et al. 2004, Neiman et al. 2011). The average

16 flood seasonality in Arizona and New Mexico is generally concentrated during the summer

17 months, and is related to the occurrence of the North American monsoon (e.g., Adams and

18 Comrie 1997) and to the passage of eastern North Pacific tropical cyclones (e.g., Wood and

19 Ritchie 2013). Over the north-central United States, the average seasonality is generally around

20 April to June, with flood events that are associated with snowmelt. As we move south towards

21 the Gulf of Mexico, the average seasonality shifts later in the spring and into the summer, in

22 relation with thunderstorm activity and mesoscale convective systems (e.g., Fritsch et al. 1986,

23 Hirschboeck 1991, Bradley and Smith 1994, Smith et al. 2000, Schumacher and Johnson 2006, 
1 Stevenson and Schumacher 2014). The summer and early fall are also the average flood seasons

2 for the Florida Peninsula, with major flooding related to North Atlantic tropical cyclones

3 (Villarini et al. 2014). Large regions of the central and eastern United States exhibit a cold

4 season climatology, with peaks in the winter and early spring. These flood events are tied to

5 extratropical cyclones and atmospheric rivers (e.g., Hirschboeck 1991, Lavers and Villarini

6 2013, Nakamura et al. 2013). The importance of tropical moisture export (organized and

7 persistent transport of moisture from the tropics towards the poles) for heavy rainfall and

8 flooding across the eastern United States was recently shown in Steinschneider and Lall (2015)

9 (see also Moore et al. (2015)). The average flood seasonality in the northeastern United States

10 tends to be concentrated in late winter into early spring, in relation with snowmelt, rain on snow

11 and rain on frozen ground (e.g., Villarini and Smith 2010). Along the U.S. East Coast, there is a

12 less spatially-coherent signal, as the ridge of the Appalachian Mountains exhibits mostly a winter

13 seasonality, with other parts of the U.S. eastern seaboard display a summer seasonality. As

14 discussed in Smith et al. (2011), this variability is due to a combination of tropical and

15 extratropical systems.

16 The map in Figure 3 (top panel) provides an overview of the average seasonality of flooding

17 across the continental United States. However, these results do not offer information about the

18 strength of the seasonality, which is summarized by the sample mean resultant length (Figure 3,

19 bottom panel). The strongest seasonality is over the western United States, where the region

20 ranging from western Washington to Colorado exhibits values of the sample mean resultant

21 length $\bar{R}$ in excess of 0.9 . This very strong seasonality indicates that flooding in these regions

22 occurs almost exclusively in the May-June months, in relation to snowmelt. Large values of $\bar{R}$

23 are also found in the northern part of the continental United States close to the Canadian border 
1 and are also related to snowmelt events. The U.S. West Coast is another part of the country with

2 strong seasonality $(\bar{R}$ values between 0.8 and 0.9$)$ associated with cold season flood events in

3 relation with atmospheric rivers. $\bar{R}$ values between 0.7 and 0.8 are found in large areas of the

4 western United States, across the northern Great Plains, into Nebraska and northern Michigan.

5 Similar values can be found in Alabama, Tennessee and Mississippi associated with extratropical

6 activity. Values of the sample mean resultant length of between 0.4 and 0.7 are characteristic of

7 the flood seasonality of high elevation areas along the U.S. West Coast (e.g., Sierra Nevada),

8 where flood events are tied to both atmospheric rivers and snowmelt events. Similarly strong

9 seasonality is also found in large areas east of the Rocky Mountains, where thunderstorms and

10 extratropical cyclones play a major role. There is a much weaker seasonality $(\bar{R}$ values smaller

11 than 0.4) in the eastern United States, including the Carolinas, Virginia, Maryland and as far

12 north as New York and Massachusetts. These are areas in which both tropical and extratropical

13 storms can cause flooding at almost any time during the year (see Figure 2, left panels; e.g.,

14 Smith et al. 2011). The Appalachian Mountains bound this region to the west and to the south

15 (see also Gamble (1997)). Similar conditions tend to characterize the flood seasonality for large

16 areas around the Gulf of Mexico, for which tropical and extratropical storms play a major role.

17 The results shown in Figure 3 provide a broad overview of the differences in flood

18 seasonality in terms of timing and strength. To characterize the shape of the seasonality, I test its

19 distribution against three possible models: circular uniform, reflective symmetric and

20 asymmetric. The circular uniform distribution represents the most basic circular model, with no

21 preferential direction and flood events can happen anytime during the year. The Rayleigh test,

22 Kuiper's $V_{n}$, Watson's $U_{2}$, and Rao's spacing test are used to test the null hypothesis of circular

23 uniformity. Figure 4 shows the stream gage locations for which there is not enough statistical 
1 evidence to reject the hypothesis of uniformity. All four tests tend to provide similar results, and

2 most of the locations are concentrated along the Appalachian Mountains and the U.S. eastern

3 seaboard. Many stations along the Gulf Coast also exhibit a uniform seasonal distribution. These

4 are also the locations with very small values of the sample mean resultant length (Figure 3,

5 bottom panel). At these locations, the flood peak distribution highlights the mixture of different

6 flood generating mechanisms, with tropical and extratropical storms playing a large role.

7 The majority of the stream gages considered in this study exhibit a reflective symmetric

8 distribution (Figure 5, top panel). These stations are generally located east of the Rocky

9 Mountains, from Kansas and Nebraska to the Appalachian Mountains and into the northeastern

10 United States. The same distribution also characterizes flooding along the U.S. West Coast,

11 Idaho, Montana, Wyoming and into Colorado. The stations for which there is enough statistical

12 evidence to reject the hypothesis of reflective symmetry are characterized as asymmetric. These

13 stream gages are generally concentrated in North Dakota, Minnesota and Wisconsin, and in the

14 high elevation regions of the Cascade Mountains and Sierra Nevada in the western United States.

15 The asymmetry in the distribution over the Northern Great Plains is likely due to flood events

16 associated with snowmelt and rain on frozen ground in the spring and mesoscale convective

17 systems in the summer (e.g., Hirschboeck 1991). In Oregon, Washington and California, the

18 main mechanisms driving the seasonality of flooding are atmospheric rivers from October to

19 February, and snowmelt events later in the spring.

20 The analyses up to this point assumed that the seasonality of flooding has not changed over

21 the study period. Here I examine whether there are changes in the seasonality over the study

22 period, and characterize the impacts that anthropogenic modifications of the watersheds

23 (urbanization and regulation) may have exerted on the seasonality of flood peaks. The presence 
1 of temporal changes is investigated using two measures of linear-circular association, the

2 Johnson-Wehrly-Mardia correlation coefficient and the Mardia's rank correlation coefficient

3 (Figure 6). The main difference between these two tests is that the former assumes a sinusoidal

4 association, while the latter does not. According to the Johnson-Wehrly-Mardia correlation

5 coefficient (Figure 6, top panel), out of 7506 stream gages, there are 365 (705) stations with a

6 statistically significant change in the seasonality at the 5\% (10\%) level. On the other hand, there

7 are 755 and 1244 stations with statistically significant changes in the seasonality of flooding at

8 the $5 \%$ and $10 \%$ levels, respectively (Figure 6, bottom panel). While these results suggest

9 temporal changes in many locations, and even more using so using the non-parametric

10 coefficient, it is difficult to identify strong spatial patterns. Even though these results indicate

11 that there may be changes in the seasonality of flooding, the tests do not tell us whether the

12 changes lead to an earlier or later flood season.

13 In addition to temporal changes, I have also examined how urbanization and regulation may

14 have affected the seasonality of flooding (Figure 7). Overall, I wish to determine the possible

15 effects of these two anthropogenic influences in terms of changes in the average seasonality,

16 concentration, and seasonal distribution of flooding within the watersheds. On the one hand,

17 there is not an overall signal of changes in the mean direction (Figure 7, top panels). On the other

18 hand, concentration is the one characteristic of flood seasonality that appears to be most

19 susceptible to change (Figure 7, middle panels). The values of concentration after regulation are

20 generally smaller than before its onset, indicating a broader seasonality, likely related to the

21 reservoir operations (storage of water and release later in the year). The impacts of urbanization

22 are less clear than those of regulation because of the small number of stations with statistically

23 significant changes. Overall, the changes in seasonal distribution (Figure 7, bottom panels) 
1 match those in the concentration of flood events, indicating that regulation, and to a lesser degree

2 urbanization, affect the strength of the seasonality of flooding, rather than its average timing.

\section{Summary and Conclusion}

This study examined the seasonality of flooding at 7506 USGS stream gaging stations across

9 the continental United States using circular statistics. The main findings can be summarized as 10 follows:

11 1. There is a strong seasonality in flooding across the United States, reflecting differences in 12 flood generating mechanisms. On average, flood events tend to be concentrated in the 13 cold season (from October to March) along the U.S. West Coast and the eastern United 14 States. The average flood seasonality is during the April-May months in areas where northeastern United States). Flood events in Florida, the southern Great Plains (from Texas to Nebraska) and in the southwestern United States tend to occur during the summer and into the early fall.

2. The strength of the flood seasonality varies across the study area. The strongest seasonality is in the western United States, from Idaho and Montana down to Utah and Colorado. A much weaker seasonality is found in areas that are subject to different flood agents during the year. This is particularly true for the stream gages located along the Appalachian Mountains and the Gulf of Mexico. 
13 . I have tested the data for three seasonal distributions (uniform, reflective symmetric and asymmetric) using tests developed for circular data. The results indicate that the stream gages located along the Appalachian Mountains, the eastern seaboard and the Gulf of Mexico exhibit circular uniformity. This means that there is no preferential time of the year in which flood peaks may occur. The majority of the stations present a reflective symmetric distribution, in particular east of the Rocky Mountains, from Kansas and Nebraska to the Appalachian Mountains and into the northeastern United States. The stream gages in North Dakota, Minnesota and Wisconsin, and on the high elevation regions of the Cascade Mountains and Sierra Nevada (western United States) have an asymmetric distribution. This distribution is likely due to the combination of two main flood generating mechanisms (e.g., atmospheric rivers and snowmelt).

4. In analyzing the stationarity of the seasonality of flooding, I did not find a very strong signal of change, or large regions with a coherent signal of change. A possible interpretation of these results is either that there is no change, or that the magnitude of the change, if present, is concealed within the noise in these records.

5. I have examined the impact of urbanization and regulation on the seasonality of flooding. These results indicate that the largest effects of these two anthropogenic modifications within the watersheds are on the strength of the flood seasonality, rather than on the average timing. Overall, regulation has led to a weaker seasonal cycle, likely due to the storage of water and later release. Future studies should consider the information about regulation and urbanization in the GAGES-II database (Falcone et al. 2010, Falcone 2011) rather than relying on the qualifying codes considered here. 
1 Acknowledgments. Gabriele Villarini acknowledges financial support from the USACE Institute

2 for Water Resources, and from the National Science Foundation under CAREER Grant AGS-

3 1349827. The author would also like to thank Dr. Lund and Dr. Agostinelli for making the 4 circular package (Agostinelli and Lund 2013) freely available in R (R Core Team 2015). The 5 help from Dr. Agostinelli, Dr. Pewsey, and Dr. Slater is gratefully acknowledged. 


\section{REFERENCES}

2 Adams, D.K., and A.C. Comrie, The North American Monsoon, Bulletin of the American

3 Meteorological Society, 78, 2197-2213, 1997

4 Agostinelli, C., and U. Lund, R package 'circular': Circular Statistics (version 0.4-7), URL

5 https://r-forge.r-project.org/projects/circular/, 2013.

6 Archer, D.R., Seasonality of flooding and the assessment of seasonal flood risk, ICE

$7 \quad$ Proceedings, 71(4), 1023-1035, 1981.

8 Barnett, T.P., J.C. Adam, and D.P. Lettenmaier, Potential impacts of a warming climate on water 9 availability in snow-dominated regions, Nature, 438, 303-309, 2005.

10 Bayliss, A.C., and R.C. Jones, Peaks-over-threshold flood database: Summary statistics and 11 seasonality, Report 121, Institute of Hydrology, Wallingford, Oxfordshire, 1993.

12 Beurton, S., and A.H. Thieken, Seasonality of floods in Germany, Hydrological Sciences 13 Journal, 54(1), 62-76, 2009.

14 Black, A.R., and A. Werritty, Seasonality of flooding: A case study of North Britain, Journal of 15 Hydrology, 195, 1-25, 1997.

16 Bradley, A.A., and J.A. Smith, The hydrometeorological environment of extreme rainstorms in 17 the Southern Plains of the United States, Journal of Applied Meteorology, 33, 1418-1431, $18 \quad 1994$.

19 Burn, D.H., Catchment similarity for regional flood frequency analysis using seasonality 20 measures, Journal of Hydrology, 202, 212-230, 1997.

21 Castellarin, A., D.H. Burn, and A. Brath, Assessing the effectiveness of hydrological similarity 22 measures for flood frequency analysis, Journal of Hydrology, 241, 270-285, 2001. 
1 Chen, L., S. Guo, B. Yan, P. Liu, and B. Fang, A new seasonal design method based on bivariate

2 joint distribution of flood magnitude and date of occurrence, Hydrological Sciences Journal, $3 \quad 55(8), 1264-1280,2010$.

4 Chen, L., V.P. Singh, S. Guo, B. Fang, and P. Liu, A new method for identification of flood 5 seasons using directional statistics, Hydrological Sciences Journal, 58(1), 28-40, 2013.

6 Chowdhury, M.R., and M.N. Ward, Seasonal flooding in Bangladesh-variability and 7 predictability, Hydrological Processes, 21, 335-347, 2007.

8 Clow, D.W., Changes in the timing of snowmelt and streamflow in Colorado: A response to 9 recent warming, Journal of Climate, 23, 2293-2306, 2010

10 Cunderlik, J.M., and D.H. Burn, The use of flood regime information in regional flood frequency 11 analysis, Hydrological Sciences Journal, 47(1), 77-92, 2001.

12 Cunderlik, J., and T.B.M.J. Ouarda, Trends in the timing and magnitude of floods in Canada, 13 Journal of Hydrology, 375, 471-480, 2009.

14 Cunderlik, J., T.B.M.J. Ouarda, and B. Bobée, Determination of flood seasonality from 15 hydrological records, Hydrological Sciences Journal, 49(3), 511-526, 2004.

16 De Michele, C., and R. Rosso, A multi-level approach to flood frequency regionalization, 17 Hydrology and Earth System Sciences, 6(2), 185-194, 2002.

18 Dhakal, N., S. Jain, A. Gray, M. Dandy, and E. Stancioff, Nonstationarity in seasonality of 19 extreme precipitation: A nonparametric circular statistical approach and its application, $20 \quad$ Water Resources Research, 51, 4499-4515, 2015.

21 Falcone, J.A., Carlisle, D.M., Wolock, D.M., and Meador, M.R., GAGES: A stream gage 22 database for evaluating natural and altered flow conditions in the conterminous United 23 States, Ecology, 91(2), 621, 2010. 
1 Falcone, J.A., GAGES-II, Geospatial Attributes of Gages for Evaluating Streamflow [digital

2 spatial dataset], available

3 http://water.usgs.gov/GIS/metadata/usgswrd/XML/gagesII_Sept2011.xml, 2011.

4 Fang, B., S. Guo, S. Wang, P. Liu, and Y. Xiao, Non-identical models for seasonal flood 5 frequency analysis, Hydrological Sciences Journal, 52(5), 974-991, 2007.

6 Fisher, N.I., Statistical analysis of circular data. Cambridge, UK, Cambridge University Press, $7 \quad 1993$.

8 Fritsch, J.M., R.J. Kane, and C.R. Chelius, The contribution of mesoscale convective weather 9 systems to the warm-season precipitation in the United States, Journal of Climate and $10 \quad$ Applied Meteorology, 25, 1333-1345, 1986.

11 Gamble, D.W., The relationship between drainage basin area and annual peak-flood seasonality 12 in the southeastern United States, Southeastern Geographer, 37(1), 61-75, 1997.

13 Hirsch, R.M., and K.R. Ryberg, Has the magnitude of floods across the USA changed with 14 global $\mathrm{CO}_{2}$ levels?, Hydrological Sciences Journal, 57(1), 1-9, 2012.

15 Hirschboeck, K.K., Flood hydroclimatology. In: Flood Geomorphology, edited by V.R. Baker, 16 R.C. Kochel and P.C. Patton, pp. 27-49. John Wiley \& Sons Inc., New York, USA, 1991.

17 Hodgkins, G.A., R.W. Dudley, and T.G. Huntington, Changes in the timing of high river flows 18 in New England over the 20 $0^{\text {th }}$ century, Journal of Hydrology, 278, 244-252, 2003.

19 Javelle, P., T.B.M.J. Ouarda, and B. Bobée, Spring flood analysis using the flood-duration20 frequency approach: Application to the provinces of Quebec and Ontario, Hydrological 21 Processes, 17, 3717-3736, 2003.

22 Johnson, R.A., and T.E. Wehrly, Measures and models for angular correlation and angular-linear 23 correlation, Journal of the Royal Statistical Society B, 39, 222-229, 1977. 
1 Köplin, N., B. Schädler, D. Viviroli, and R. Weingartner, Seasonality and magnitude of floods in

2 Switzerland under future climate change, Hydrological Processes, 28, 2567-2578, 2014.

3 Koutroulis, A.G., I.K. Tsanis, and I.N. Daliakopoulos, Seasonality of floods and their

4 hydrometeorologic characteristics in the island of Crete, Journal of Hydrology, 394, 90-100, 52010.

6 Lavers, D.A., and G. Villarini, Atmospheric rivers and flooding over the central United States, 7 Journal of Climate, 26(20), 7829-7836, 2013.

8 Lecce, S.A., Seasonality of flooding in North Carolina, Southeastern Geographer, 40(2), 168$9 \quad 175,2000$.

10 Lee, A., Circular data, WIREs Computational Statistics, 2(4), 477-486, 2010.

11 Lins, H.F., and J.R. Slack, Streamflow trends in the United States, Geophysical Research Letters, $12 \quad 26,227-230,1999$.

13 Macdonald, N., Trends in flood seasonality of the River Ouse (Northern England) from archive 14 and instrumental sources since AD 1600, Climatic Change, 110, 901-923, 2012.

15 Magilligan, F.J., and B.E. Graber, Hydroclimatological and geomorphic controls on the timing 16 and spatial variability of floods in New England, USA, Journal of Hydrology, 178, 159-180, $17 \quad 1996$.

18 Mallakpour, I., and G. Villarini, The changing nature of flooding across the central United 19 States, Nature Climate Change, 5, 250-254, 2015.

20 Mardia, K.V., Statistics of directional data, London: Academic Press, 1972.

21 Mardia, K.V., Linear-circular correlation coefficients and rhythmometry, Biometrika, 63, 403$22 \quad 405,1976$. 
1 McCabe, G.J., and M.P. Clark, Trends and variability in snowmelt runoff in the western United

2 States, Journal of Hydrometeorology, 6, 476-482, 2005.

3 McCuen, R.H., and R.E. Beighley, Seasonal flow frequency analysis, Journal of Hydrology, $4 \quad 279(1-4), 43-56,2003$.

5 Mcdonald, N., Trends in flood seasonality of the River Ouse (Northern England) from archive 6 and instrumental sources since AD 1600, Climatic Change, 110, 901-923, 2012.

7 McEwen, L.J., Flood seasonality and generating conditions in the Tay catchment, Scotland from 81200 to present, Area, 38.1, 47-64, 2006.

9 Moore, B.J., K.M. Mahoney, E. Sukovich, R. Cifelli, and T.M. Hamill, Climatology and 10 Environmental Characteristics of extreme precipitation events in the southeastern United 11 States, Monthly Weather Review, 134, 718-741, 2015.

12 Nakamura, J., U. Lalla, Y. Kushnir, A.W. Robertson, and R. Seager, Dynamical structure of 13 extreme floods in the U.S. Midwest and the United Kingdom, Journal of Hydrometeorology, $14 \quad 14,485-504,2013$.

15 Neiman, P.J., L.J. Schick, F.M. Ralph, M. Hughes, and G.A. Wick, Flooding in western 16 Washington: The connection to atmospheric rivers, Journal of Hydrometeorology, 12, 1337$17 \quad 1358,2011$.

18 Ouarda, T.B.M.J., J.M. Cunderlik, A. St-Hilaire, M. Barbet, P. Bruneau, and B. Bobée, Data19 based comparison of seasonality-based regional flood frequency methods, Journal of $20 \quad$ Hydrology, 330, 329-339, 2006.

21 Pewsey, A., Testing circular symmetry, Canadian Journal of Statistics, 30, 591-600, 2002.

22 Pewsey, A., M. Neuhäser, and G.D. Ruxton, Circular statistics in R, 2013. 
1 Parajka, J., S. Kohnová, G. Bálint, M. Barbuc, M. Borga, P. Claps, S. Cheval, A. Dumitrescu, E.

2 Gaume, K. Hlavčová, R. Merz, M. Pfaundler, G. Stancalie, J. Szolgay, and G. Blöschl, 3 Seasonal characteristics of flood regimes across the Alpine-Carpathian range, Journal of $4 \quad$ Hydrology, 394(1-2), 78-89, 2010.

5 Peterson, T.C., R.R. Heim, R. Hirsch, D.P. Kaiser, H. Brooks, N.S. Diffenbaugh, R.M. Dole, J.P.

6 Giovannettone, J. Guirguis, T.R. Karl, R.W. Katz, K. Kunkel, D. Lettenmaier, G.J. McCabe, 7 C.J. Paciorek, K.R. Ryberg, S. Schubert, V.B.S. Silva, B.C. Stewart, A.V. Vecchia, G. 8 Villarini, R.S. Vose, J. Walsh, M. Wehner, D. Wolock, K. Wolter, C.A. Woodhouse, and D. 9 Wuebbles, Monitoring and understanding changes in heat waves, cold waves, floods and 10 droughts in the United States: State of knowledge, Bulletin of the American Meteorological 11 Society, 94(6), 821-834, 2013.

12 R Core Team, R: A language and environment for statistical computing, R Foundation for 13 Statistical Computing, Vienna, Austria. URL https://www.R-project.org/, 2015

14 Ralph, F.M., P.J. Neiman, G.A. Wick, S.I. Gutman, M.D. Dettinger, D.R. Cayan, and A.B. 15 White, Flooding on California's Russian River: Role of atmospheric rivers, Geophysical 16 Research Letters, 33, L13801, doi:10.1029/2006GL026689, 2006.

17 Robson, A., and D. Reed, Flood estimation handbook - volume 3, Statistical Procedures for 18 Flood Frequency Estimation, Institute of Hydrology, Wallingford, Oxfordshire, 1999.

19 Rossi, F., M. Fiorentino, and P. Versace, Two-component extreme value distribution for flood20 frequency analysis, Water Resources Research, 20, 847-856, 1984.

21 Rust, H.W., D. Mauran, and T.J. Osborn, Modelling seasonality in extreme precipitation - A UK 22 case study, The European Physical Journal, 174, 99-111, 2009. 
1 Schumacher, R.S., and R.H. Johnson, Characteristics of U.S. extreme rain events during 1999-

2 2003, Weather and Forecasting, 21, 69-85, 2006.

3 Sivapalan, M., G. Blöschl, R. Merz, and D. Gutknecht, Linking flood frequency to long-term

4 water balance: Incorporating effects of seasonality, Water Resources Research, 41, W06012, 5 doi:10.1029/2004WR003439, 2005.

6 Slater, L.J., M.B. Singer, and J.W. Kirchner, Hydrologic versus geomorphic drivers of trends in 7 flood hazard, Geophysical Research Letters, 42(2), 370-376, 2015.

8 Smith, J.A., M.L. Baeck, J.E. Morrison, and P. Sturdevant-Rees, Catastrophic rainfall and 9 flooding in Texas, Journal of Hydrometeorology, 1, 5-25, 2000.

10 Smith, J.A., G. Villarini, and M.L. Baeck, Mixture distributions and the climatology of extreme 11 rainfall and flooding in the Eastern US, Journal of Hydrometeorology, 12(2), 294-309, 2011.

12 Steinschneider, S., and U. Lall, Daily precipitation and tropical moisture exports across the 13 eastern United States: An application of archetypal analysis to identify spatiotemporal 14 structure, Journal of Climate, 28, 8585-8602, 2015.

15 Stevenson, S.N., and R.S. Schumacher, A 10-year survey of extreme rainfall events in the central 16 and eastern United States using gridded multisensory precipitation analyses, Monthly 17 Weather Review, 142, 3147-3162, 2014.

18 Stewart, I.T., D.R. Cayan, and M.D. Dettinger, Changes in snowmelt runoff timing in western 19 North America under a "business as usual" climate change scenario, Climatic Change, 62, $20 \quad 217-232,2004$.

21 Stewart, I.T., D.R. Cayan, and M.D. Dettinger, Changes toward earlier streamflow timing across 22 western North America, Journal of Climate, 18, 1136-1155, 2005. 
1 Villarini, G., and J.A. Smith, Flood peak distributions for the Eastern United States, Water

2 Resources Research, doi:10.1029/2009WR008395, 46, W06504, 2010.

3 Villarini, G., F. Serinaldi, J.A. Smith, and W.F. Krajewski, On the stationarity of annual flood

4 peaks in the continental United States during the 20th century, Water Resources Research, $5 \quad$ 45, W08417, doi:10.1029/2008WR007645, 2009.

6 Villarini, G., R. Goska, J.A. Smith, and G.A. Vecchi, North Atlantic tropical cyclones and U.S. 7 flooding, Bulletin of the American Meteorological Society, 95(9), 1381-1388, 2014.

8 Vogel, R.M., C. Yaindl, and M. Walter, Nonstationarity: Flood magnification and recurrence 9 reduction factors in the United States, Journal of the American Water Resources Association, $10 \quad 47(3), 464-474,2011$.

11 Wallraff, H.G., Goal-oriented and compass-oriented movements of displaced homing pigeons 12 after confinement in differentially shielded aviaries, Behavioral Ecology and Sociobiology, $13 \quad 5,201-225,1979$.

14 Watson, G.S., Goodness-of-fit tests on a circle II, Biometrika, 49, 57-63, 1962.

15 Wheeler, S., and G.S. Watson, A distribution -free two sample test on the circle, Biometrika, 51, $16 \quad 256-257,1964$.

17 Wood, K.M., and E.A. Ritchie, An updated climatology of tropical cyclone impacts on the 18 southwestern United States, Monthly Weather Review, 141, 4322-4336, 2013. 

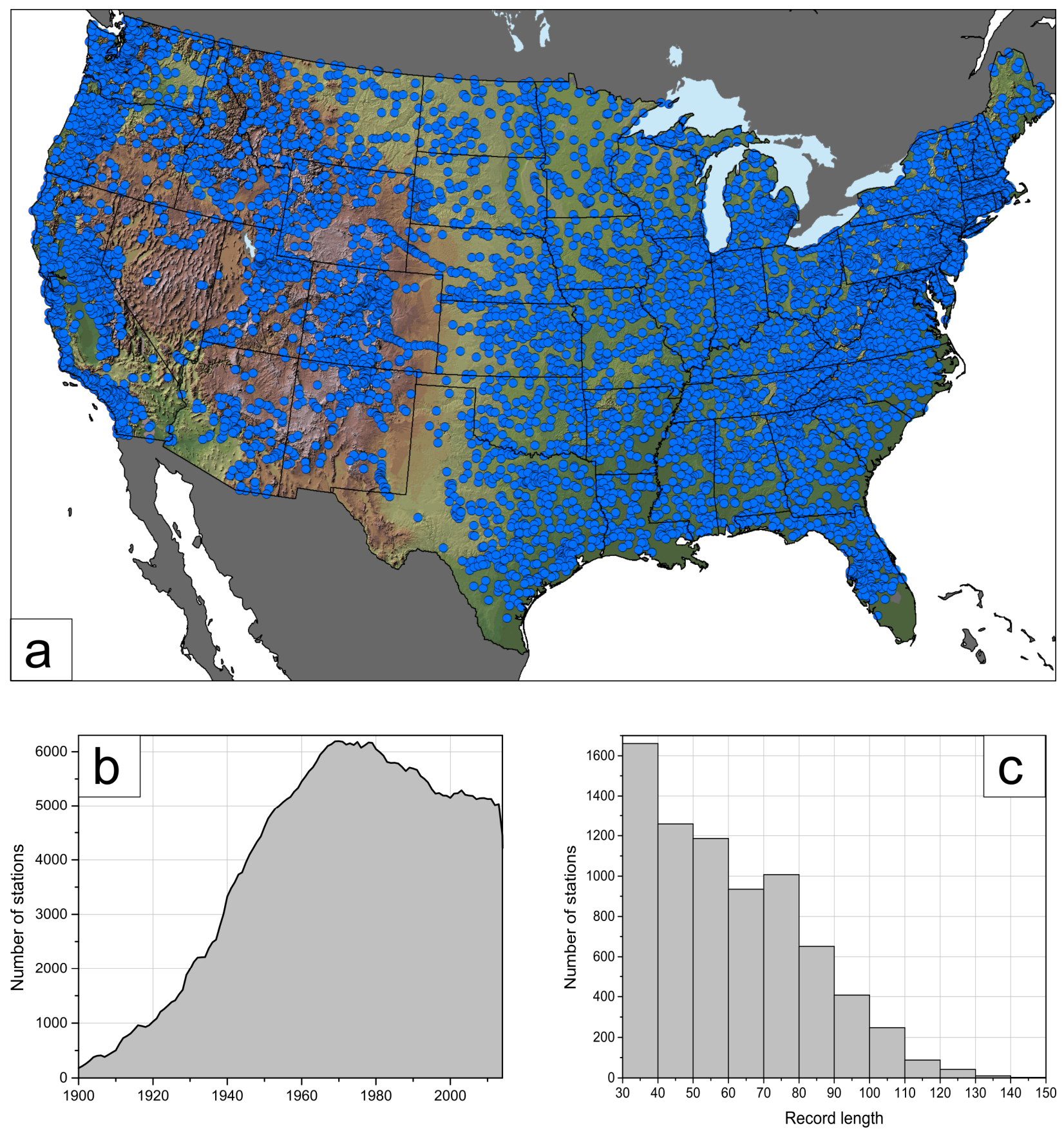

2 FIG. 1: a) Location of the 7506 stream gage stations with at least 30 years of instantaneous

3 annual maximum peak discharge data. b) Time series of the number of stream gage stations

4 available in a given year. c) Histogram of the record length for the 7506 stations considered in

5 this study. 
Uniform

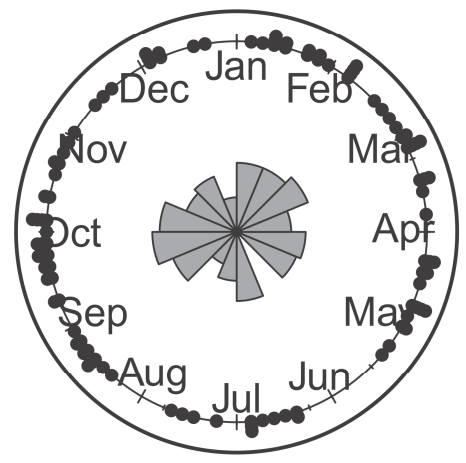

1

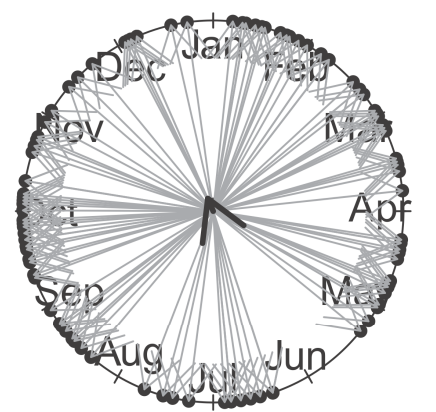

Reflective symmetric
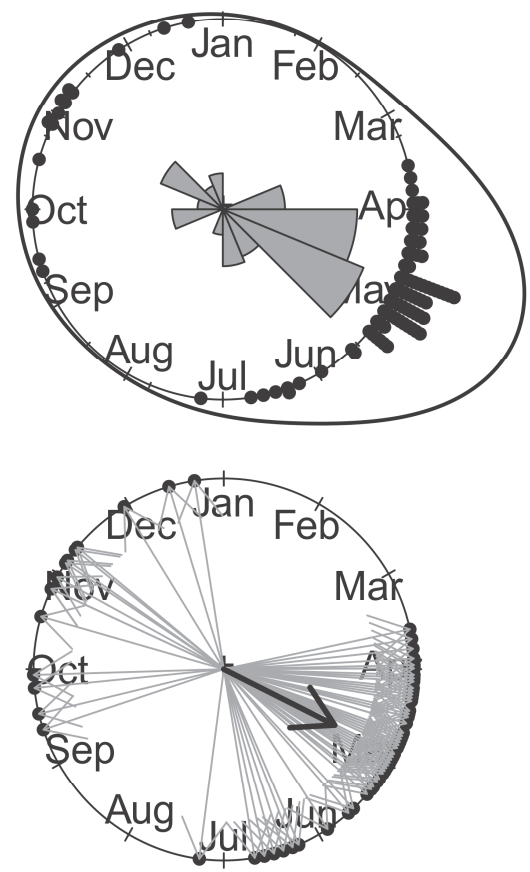

Asymmetric
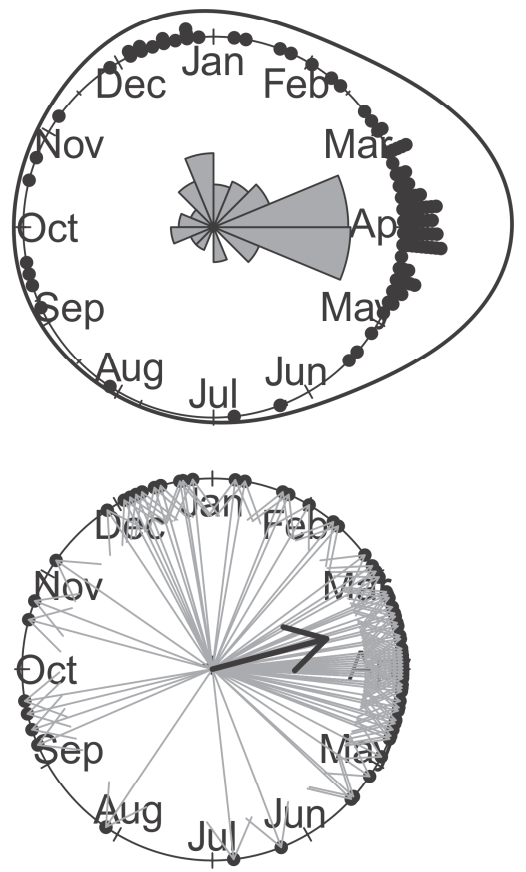

2 FIG. 2: Top panels: Example of the use of circular statistics to characterize the seasonality of

3 annual maximum peak discharge for uniform (Roanoke River at Roanoke Rapids, North

4 Carolina; USGS ID 02080500; left panels), reflective symmetric (East Brach Penobscot River at

5 Grindstone, Maine; USGS ID 01029500; middle panels), and asymmetric (Souhegan River at

6 Merrimack, New Hampshire; USGS ID 01094000; right panels) distributions. The black points

7 on the circle represent the raw data; the grey wedges in the middle of the circles show the rose

8 diagram, with the areas of each sector highlighting the relative frequencies in 16 bins; the black

9 solid line outside the circles indicates the kernel density. Bottom panels: Circular plot showing

10 the direction of each of the annual maximum peak discharge data for the three stream gage

11 locations in the top row. The black points on the circle represent the raw data and the grey

12 arrows within it the associated direction. The black solid arrow represents the mean resultant

13 vector. 


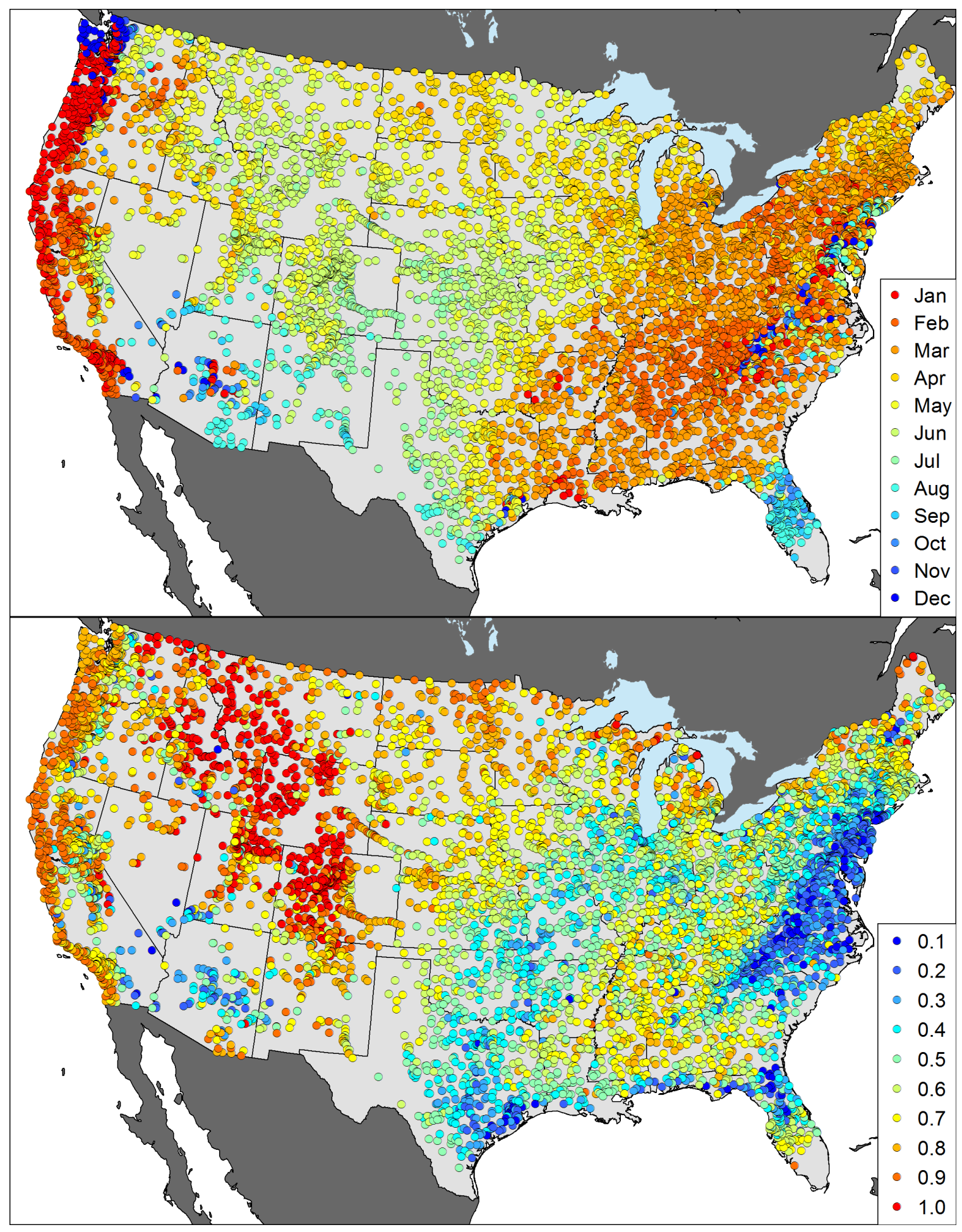

2 FIG. 3: Maps showing the sample mean direction (top panel) and the sample mean resultant

3 length (bottom panel) of the seasonality of flooding. 


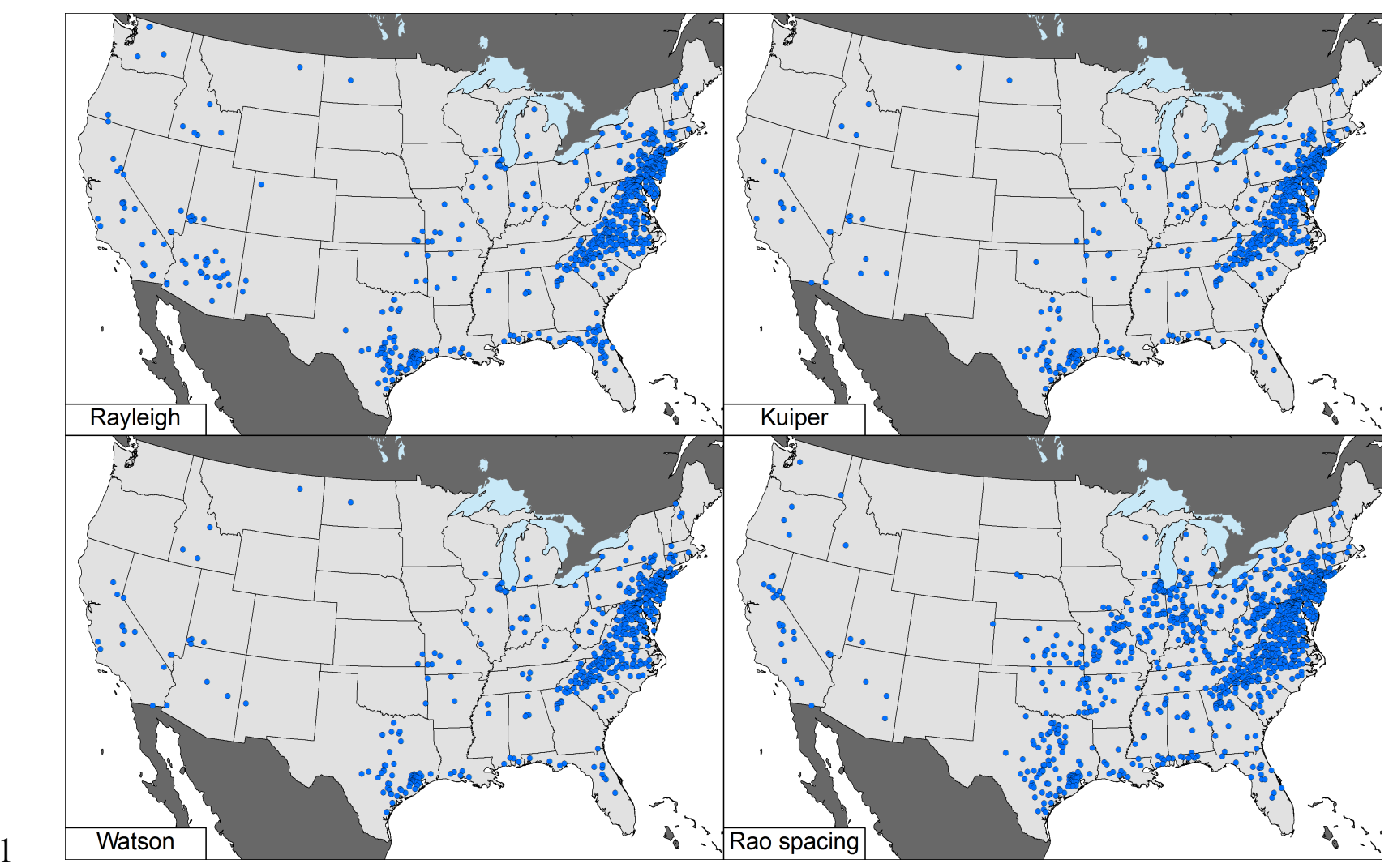

2 FIG. 4: Maps showing the results of four tests for circular uniformity (Rayleigh test, Kuiper's $\mathrm{V}_{\mathrm{n}}$,

3 Watson's U², and Rao's spacing test). The blue circles represent the stream gages for which there

4 is not enough statistical evidence at the 5\% level to reject the null hypothesis of circular 5 uniformity based on each of these four tests. 


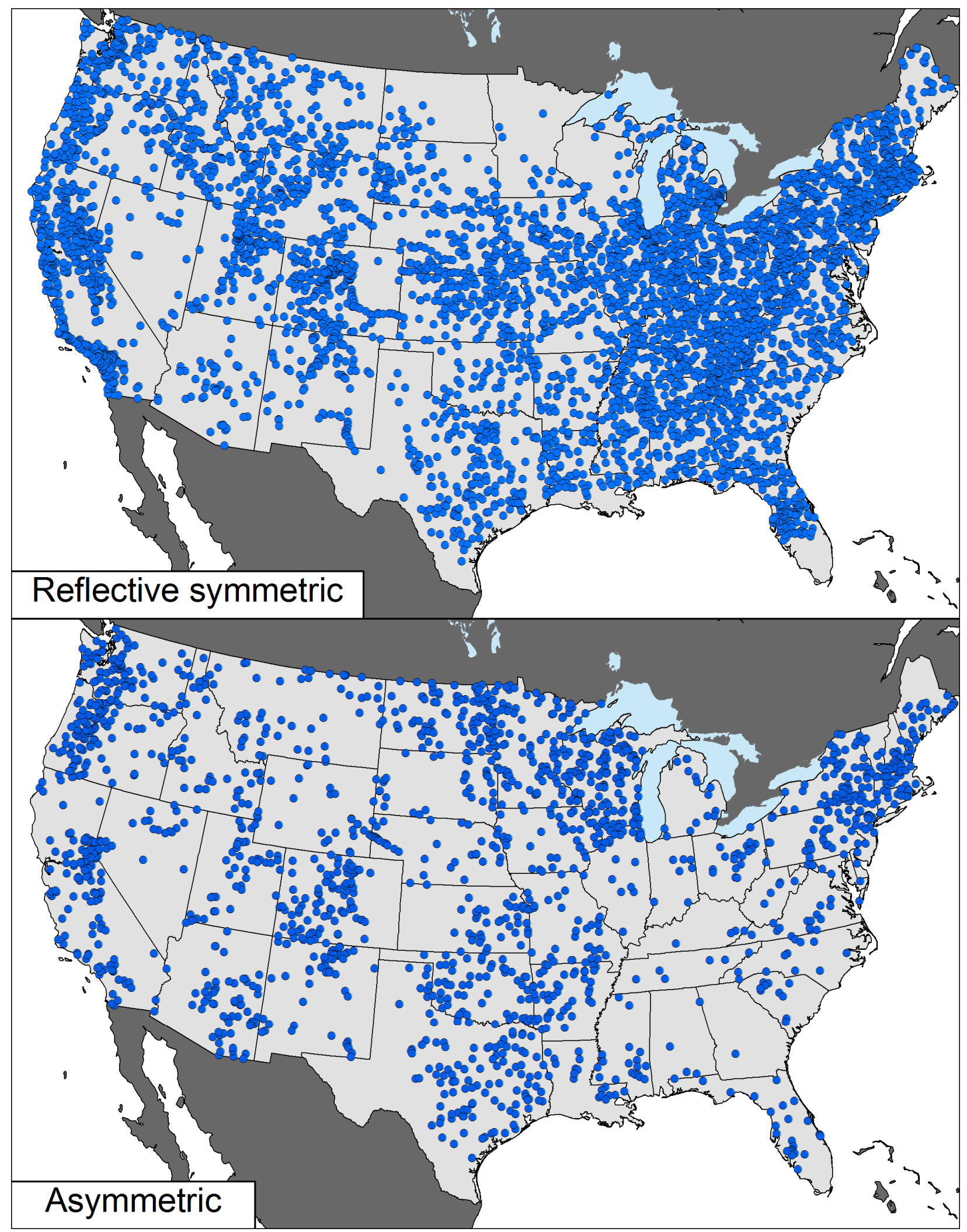

2 FIG. 5: Top panel: Maps showing the results of the test for reflective symmetry. The blue circles

3 represent the stream gages for which there is not enough statistical evidence at the 5\% level to 
1 reject the null hypothesis of reflective symmetry. Bottom panel: The blue circles represent the 2 stream gages for which there is enough statistical evidence at the $5 \%$ level to reject the null 3 hypothesis of reflective symmetry. These stations are identified as having an asymmetric 4 distribution. 


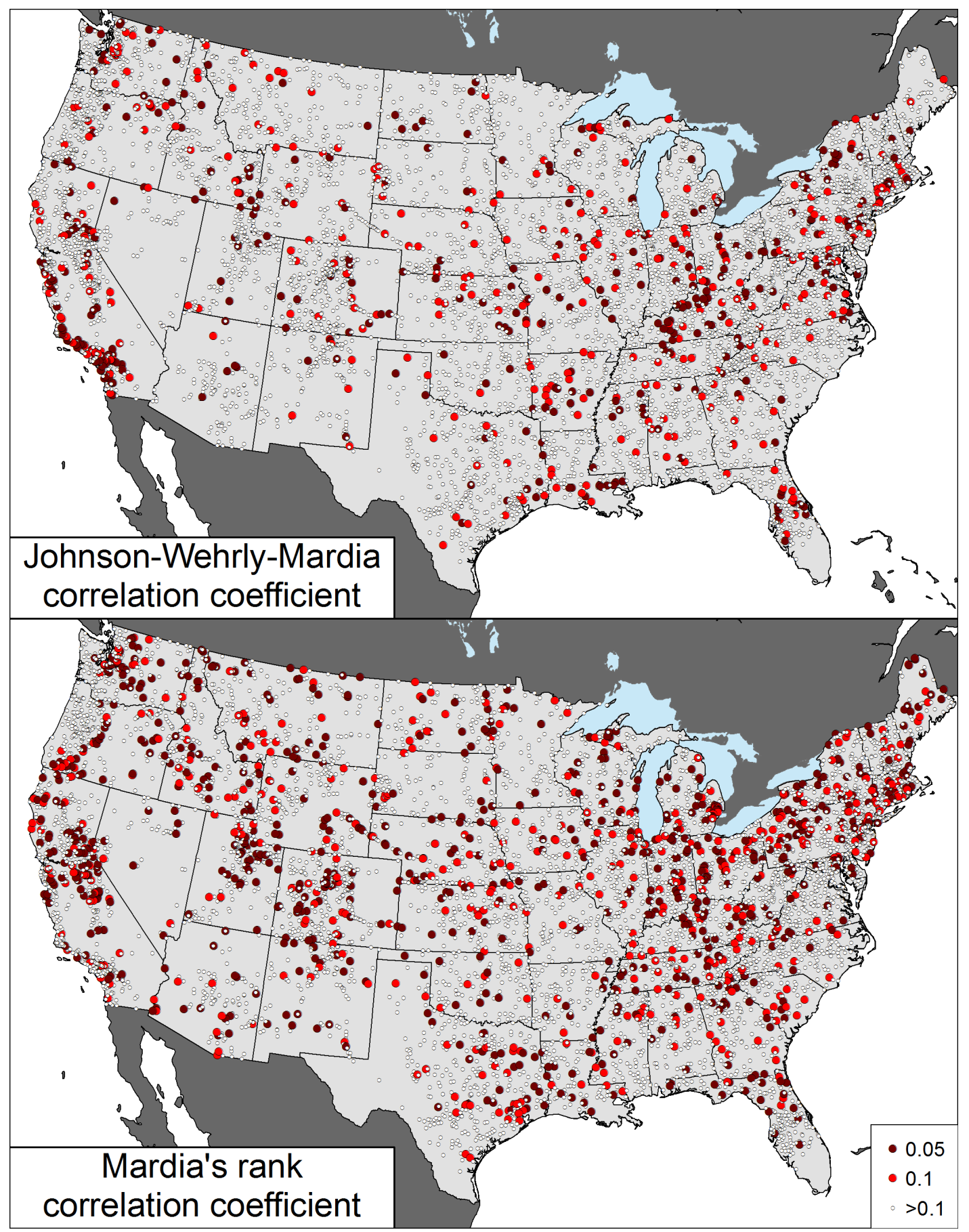

2 FIG. 6: Examination of the effects presence of temporal nonstationarities in the seasonality of

3 flooding according to the Johnson-Wehrly-Mardia correlation coefficient (top panel) and to the

4 Mardia's rank correlation coefficient (bottom panel). Results are shown at significant at the 5\%,

$5 \quad 10 \%$ and greater than $10 \%$ level. 


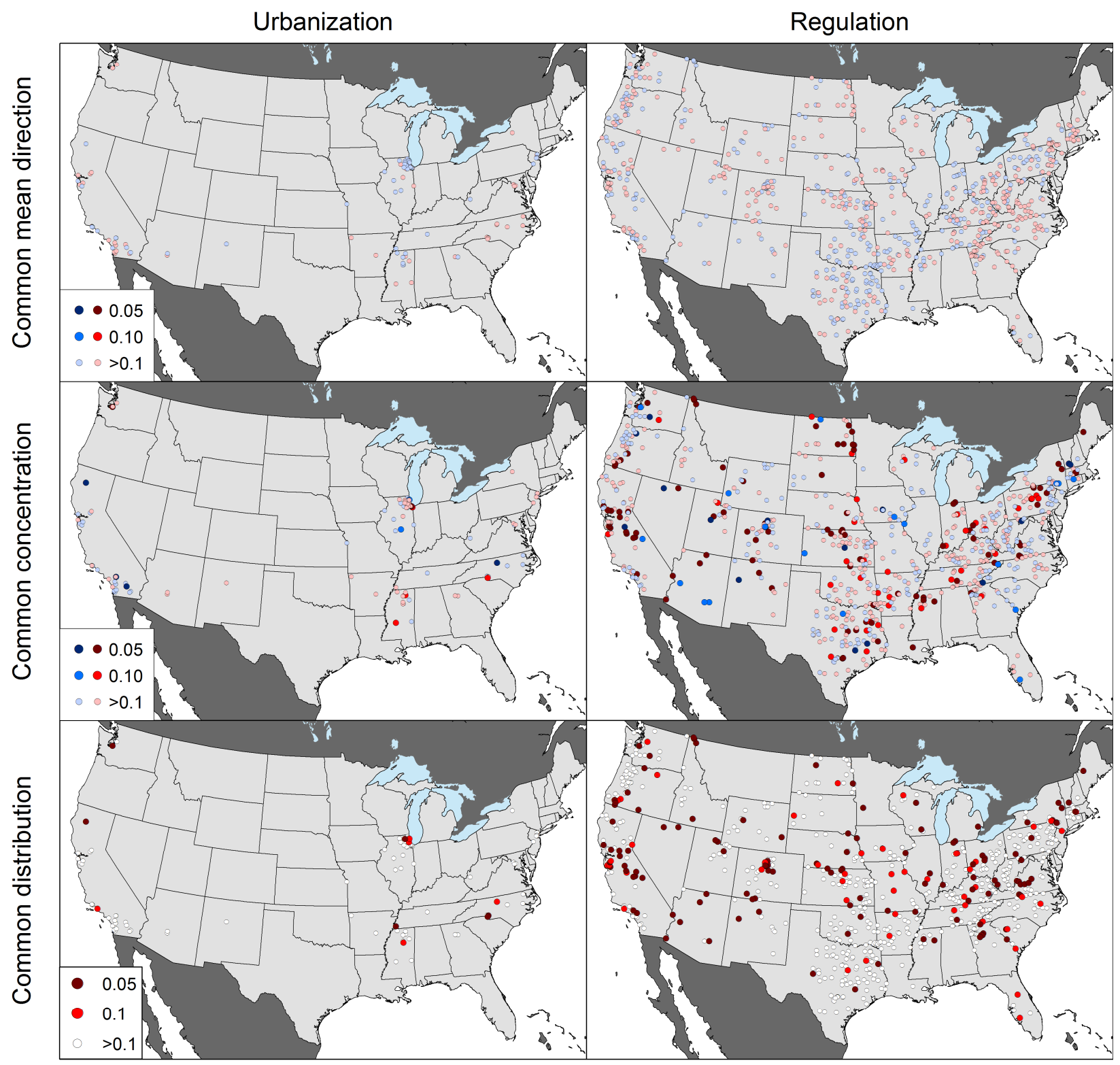

2 FIG. 7: Examination of the effects of urbanization (left panels) and regulation (right panels) on

3 the seasonality of flooding. Tests are performed to detect differences in the mean direction (top

4 panels), in the concentration (middle panels), and in the distribution (bottom panels). The results

5 are stratified in terms of statistical significance (p-value smaller than 0.05 and 0.1 , or larger than

6 0.1). In the top two rows, the blue (red) colors indicate that the mean direction or concentration

7 before regulation or urbanization are smaller (larger) than after their onset. 